\section{From an exasperated pathologist}

To the Editor: I have been a histopathologist for 5 years, and am now practising in a regional teaching hospital. I see incredible pathology, but to the detriment of the population who are biopsied. I see gross pathology - the ugly blue tumour literally stares back at me on nakedeye examination of my slide.

My office is a mess. The boards are piled up on every conceivable work surface, and I can't remember the last time I saw my desk calendar - it is well and truly buried. I am so busy that I cannot write an article in under a year. On that note, I fear the day open access becomes the norm, because we cannot afford to pay in dollars and pounds to have our work published. I fear the day when all histological diagnoses must be supported by molecular investigations, because these guidelines are developed in First-World institutions without a thought to the resources available to pathologists in the underdeveloped parts of the world.

I studied medicine for the noble reason of wanting to help others, and every day I feel that I make a difference. I send out histological diagnoses that will expedite treatment, as quickly and as accurately as I can. There is no reason why the underprivileged should not get a first-class pathological report. Almost everything I diagnose is malignant and marked 'urgent', and I feel post-traumatic stress disorder symptoms coming on. I must ask my psychiatrist husband if there is such a thing as work-related PTSD. I need him to keep me in check; his raised eyebrow lets me know I'm sounding hysterical. I should keep going, he always says. And keep going I will, because I am afraid - afraid that if I leave they will get left, the biopsies and the patients of Soweto.

We live in a world of contrasts. I am reminded of this every day as I turn my Mercedes (albeit bottom of the range) into the hospital grounds and stop to let small children cross the entrance on their way to school. They walk with schoolbags bigger than themselves, and I am happy that they are going to school. I silently pray, 'I hope I never have to diagnose your biopsy with tumour.'

All is not morbid. I have a corner office with a view of the entire hospital, and the warm sun shines on me as I sign out my cases. The birds perch on the window ledge and peck at the window to greet me. And when I close my door to leave work every day, I go home to four beautiful children who greet me with such vigour that I am rejuvenated for the next day and all the atrocities it may hold. There are people all over the world who service war-stricken and diseaseburdened communities. This very hospital is serviced by dedicated practitioners who worked tirelessly in the pre-HIV years and may still be hobbling around the corridors in the post- (dare I dream?) HIV era. We are so inundated with service delivery that there is no opportunity for research and publications - those elusive academic components that ensure a brisk climb up the career ladder. The point is, not to lose faith. Every little bit counts, and when I meet my maker at the pearly gates I can honestly say I tried. No tombstone, I think, has ever read 'Here lies the greatest pathologist that ever lived'!

\section{Reena Dhansukh Mohanlal}

Department of Anatomical Pathology, School of Pathology, Faculty of Health Sciences, University of the Witwatersrand and National Health Laboratory Service, Chris Hani Baragwanath Academic Hospital, Johannesburg, South Africa reena.mohanlal@nhls.ac.za;reenadm@mweb.co.za

PS. This letter took me 7 days to write. I found it quite therapeutic

S Afr Med J 2017;107(1):13. DOI:10.7196/SAMJ.2017.v107i1.12079 